\title{
Oil price shocks, stock market returns, and volatility spillovers: a bibliometric analysis and its implications
}

\author{
Muhammad Farhan Bashir ${ }^{1}$ (D)
}

Received: 28 September 2021 / Accepted: 21 December 2021 / Published online: 19 January 2022

(c) The Author(s), under exclusive licence to Springer-Verlag GmbH Germany, part of Springer Nature 2022

\begin{abstract}
The current research paper identifies the current dynamics in the oil price-stock market nexus to provide a research overview and suggest further research directions. We used bibliometrix R package to examine 684 studies to identify research trends in oil price shocks, stock market returns, and volatility spillover effects. We recognize the most influential authors, publications, and research institutions and their significance within the current scientific literature. We further analyzed research themes to observe impediments in the existing literature and suggest new research directions to summarize that disaggregated sectoral analysis and meta-analysis approach by including moderator analysis will broaden the research contribution in the future. Lastly, we conclude our investigation by identifying new research avenues.
\end{abstract}

Keywords Oil price shocks $\cdot$ Stock market returns $\cdot$ Volatility spillover $\cdot$ Bibliometric analysis

\section{Introduction and literature review}

Energy is the most basic requirement of the modern economic cycle of any economy as it is vital input in key economic sectors but is also critical in ensuring national security and stability of economic policies (Ma et al. 2021a; Bashir et al. 2015; Talbi et al. 2020; Hussain et al. 2021). It has been estimated that oil is the most common energy source with approximately $1 / 3$ share of overall energy consumption. Not only is oil the single most widely used energy material, but it is also a unique natural resource that bestows political and economic power to those countries possessing abundant oil reserves (Bashir et al. 2020, 2021 a,b). In recent years, energy demand from European and North American economies has slowed down considerably, and the demand for energy resources has shifted to the emerging Asian economies. According to Bashir et al. (2022), although the growth in demand for energy resources has slowed down, the share of oil in energy has increased steadily in recent years as oil demand has increased significantly in 2018 and

Responsible Editor: Nicholas Apergis

Muhammad Farhan Bashir

farhan.paks89@gmail.com; farhan.paks@csu.edu.cn

1 Business School, Central South University, Changsha 410083, Hunan, People's Republic of China
2019, with daily oil consumption of 96.5 million barrels. The USA has the largest share of world oil consumption with $20.3 \%$, followed by China and India with $12.8 \%$ and $4.6 \%$ (Xia et al. 2022). According to IEA, due to the economic policies of emerging economies (Bashir et al. 2021c,d), demand for fossil fuels will increase by $30 \%$ until the year 2040, with expected daily oil consumption to reach 103.5 million barrels. As a consequence, crude oil has become the most traded commodity but also carries a major influence on emerging and industrial economies as sudden shifts in oil prices not only affect economic policies, but these changes also impact stock markets with the main conclusion that unexpected oil price shocks have a significant bearing on the financial markets (Bashir et al. 2021h).

Investigating the association between stock markets, oil prices, and spillover effects is important as it allows investors to hedge portfolio risks from sudden market shifts. Bastianin et al. (2016) emphasized that oil price changes not only affect the costs but also have indirect bearings on the business cycles and stock market volatility. Huang et al. (1996) researched oil prices shifts to find a strong relationship between oil future contracts and stock trading of oil companies; and reported no significant impact on the returns of the general share index. Jones and Kaul (1996) reported that oil price shocks lead to a negative reaction in the international stock markets' trading activities. Sadorsky (1999) indicated that oil prices play an important role in 
stock returns, and oil price shocks carry asymmetric effects on the domestic economies. Faff and Brailsford (1999) analyzed the association between stock returns and oil prices in Australia to articulate a positive association between oil prices and stock returns of the fossil fuel industry. Additionally, they also reported a negative association between stock returns in transportation and packaging industries and oil prices. Ciner (2001) indicated a nonlinear causal association between oil future contracts and S\&P 500 index returns. Fong and See (2002) and Nomikos and Pouliasis (2011), by using the MS-GARCH model, reported similar outcomes.

Huang et al. (2005) researched Japan, Canada, and the USA to examine the impact of oil price volatility and oil price changes over real stock returns and industrial production levels to report nonlinear threshold effects; change in oil volatility or price has a significant impact on macroeconomic variables but only if the change is above a certain threshold. Asteriou and Bashmakova (2013) used a multifactor modeling approach in Central and Eastern European countries to indicate that stock returns have a statistically significant and negative association with oil price shocks (Ma et al. 2021b,c). Asteriou et al. (2013), by taking into account that whether countries are oil exporters or oil importers, analyzed the association between stock markets and sudden shifts in oil prices to summarize that changes in oil prices have significantly higher impact on stock markets in oil-importing countries than oil-exporting economies. Chang et al. (2010) used the DCC-GARCH model to report the negative conditional correlation association between S\&P 500, Dow Jones, NYSE, FTSE100, and Brent prices. Bouri (2015) used causality-in-variance methodology to document risk spillover effects between Jordanian stock market returns and global oil prices to analyze pre and post 2008 financial crisis, where the pre-crisis period showed no spillovers between stock returns and global oil price shifts, whereas the post-crisis period showed one-way risk spillover effects from oil price changes towards stock market returns (Liu et al. 2018; Ma et al. 2021d).

Keeping in mind the above-mentioned discussion, we research oil price shocks, stock market returns, and spillover effects to highlight research trends through bibliometric analysis to provide analytical overview of knowledge map regarding in the published scientific articles (Hirsch, 2005). In recent years, a number of studies have used bibliometric analysis to overview a number of research topics. In an early study, Mao et al. (2015a, b) provided oversight of developments in alternative energy for research publications from 1994 to 2003 through bibliometric analysis. Likewise, similar approach was adopted by Zhang et al. (2016) and Chen et al. (2017) to investigate research trends in carbon taxation and the impact of sustainability policies over firm performances. In recent studies, Bashir et al. (2021e, f, g) and Shahbaz et al. (2021) used bibliometric approach to provide systematic overview of environmental taxes, environmental Kuznets curve, One Belt One Road publications, and tourism-environmental degradation nexus, respectively. This encourages us to explore the lack of analysis regarding the publications addressing how oil prices affect stock market returns and how possible spillover effects may affect the stock performance and economic progress in general (Sultan et al. 2021).

As stated earlier, the current paper focuses on the dynamics and main research areas of oil price shocks, stock market returns, and volatility spillover effects and suggests research gaps for future research projects. To the best of our knowledge, current research is the pioneering attempt to combine systematic literature and bibliographic analysis on oil price volatility and stock market returns, which enables us to address the following research agendas: RQ1: what is the publication and citation trend in current literature? RQ2: what is the publication trend in most influential journals? RQ3: what are the most authentic academic publications? RQ4: what are the most frequent keywords? RQ5: which influential authors and research institutions have contributed most in recent years? RQ6: what is the state of research collaboration in current literature? RQ7: what is the intellectual structure of current literature? RQ8: which indicators influence co-occurrence networks in current literature? RQ9: how the most popular research themes have evolved over time? RQ10: which issues hamper oil price-stock market return nexus? and RQ11: which areas of existing literature require further research?

Previous studies of Degiannakis et al. (2018) and Nazlioglu et al. (2020) are limited to content analysis; within the same context, Lin and Su (2020) performed a systematic literature review. Current research is distinct from existing literature in the following ways. First, we are the first research to investigate the impact of oil price volatility on the stock market returns and possible spillover effects through bibliometric analysis and answer distinct RQs. Also, we critically identify the research gap in current literature to provide research directions for future studies.

\section{The procedure of bibliometric analysis}

We follow five research steps defined by Zupic and Čater (2015) as the procedure for bibliometric analysis. Figure 1 represents the five steps to investigate bibliometric analysis.

\section{Scheme of study}

Current institutional and regulatory reforms raise many questions regarding the impact of oil price volatility, stock market returns, and spillover effects. In this context, we investigate current literature and provide holistic means 
Fig. 1. Bibliometrics analysis procedure

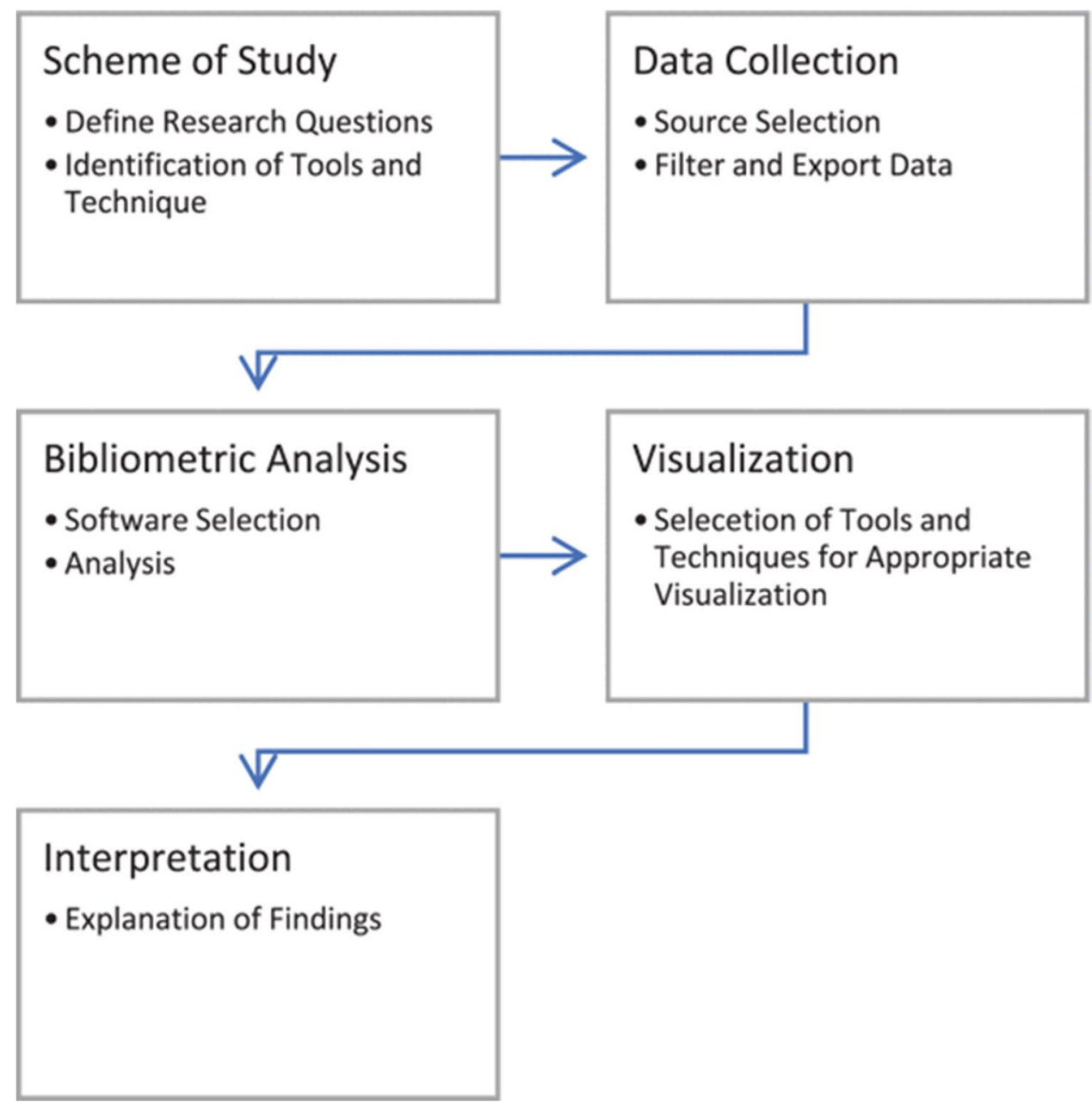

for future research. We answer research questions through descriptive statistics and finding core affiliations, publications, countries, authors, and sources of economic literature. For core authors and core sources, we consider annual publications, total citations, and source impact. Furthermore, we use Bradford's law to identify core sources, which divides the sampled studies into three distinct zones, where zone 1 is considered nuclear zones as it includes highly productive sources, zone 2 includes moderately productive, and lastly, zone three consists of low production (Wardikar \& Gudadhe 2013). Our approach also enables us to suggest top affiliations and countries based on total citations and publication frequency.

Analysis of key themes and core areas is significant in linking various research streams to identify future research directions. In this regard, we rely on thematic evolution thematic map and co-occurrence map. We include keywords plus for the aforementioned analysis to identify and link different research areas and investigate the knowledge structure of current research ( $\mathrm{Li}$ et al. 2016). Keywords plus provide more significant descriptive trends as they help express research contents succinctly than the author's keywords
(Tripathi et al. 2018). For bibliometric analysis, we use "biblioshiny" tool from R-program to identify research themes in current literature.

\section{Research objectives and analytical techniques}

The current study attempts to provide systematic literature review of oil price volatility, impact stock market returns, and provide means to improve economic literature. Our objective is to identify core institutions, countries, authors, and research publications using "biblioshiny" ("bibliometrix 3.0"). Furthermore, we aim to identify vital research themes through science mapping techniques of co-occurrence and co-citation analysis. The application of these research tools allows us to perform a comprehensive analytical review and identify limitations in current literature.

\section{Selection of dataset}

We rely on two segments to compose the bibliometric data for current research. During the first segment, we select the research articles from Web of Science (WOS), as it provides 
the most comprehensive scientific results. Next, we form the search query to select literature and apply various filters so that optimal results match our research objectives. The final search query consists of "TITLE-ABS-KEY ("oil price" OR "oil prices" OR "oil price volatility" AND "stock market" or "stock market returns" AND "spillover" or "spillover effects" AND (LIMIT-TO (SRCTYPE, “j”)) AND (LIMITTO (PUBSTAGE, “final”)) AND (LIMIT-TO (DOCTYPE, “ar")) AND (EXCLUDE (PUBYEAR, 1998)). The final search outcomes consist of 985 research articles. We limit our search query to find the English language to perform bibliometric analysis; lastly, we manually analyze the research articles and exclude 301 articles to meet the objectives of current research; our sample size comprises 684 articles.

\section{Bibliometric analysis and visualization}

We use "biblioshiny," under the Bibliometrics R package to perform the bibliometric analysis, which is designed to provide means for bibliometric and scientometric analysis using the categories of intellectual structure, social structure, conceptual structure, authors, documents, and sources. Biblioshiny allows obtaining multiple results through graphs and tables, which offers distinct features than other bibliometric software.

Table 1 provides descriptive statistics, which consists of useful information to understand before moving on with the rest of the analysis. We have finalized 684 research articles authored by 1198 researchers, where 93 publications are single-authored, which indicates a higher degree of research collaboration. Documents per author are 1.75, which means statistically single author has published more than one research paper.

The annual publication and citation trends are shown in Figs. 2 and 3, respectively. Annual publication trends can be divided into two time periods, the first until 2012; there is limited research contribution; the second time period is from 2012 onwards, where there has been a significant increase in the research contribution. The annual citation trend can also be sub-categorized into similar research categories, where there have been significant citations of literature related to oil prices, stock market returns, and spillover effects.

To further the analysis, we examine the main research themes, countries, and key journals. Figure 4 presents the three-fold analysis of oil prices, stock market returns, and spillover effects with key research themes in the middle, countries on the right, and research journals on the left side. The figure indicates that oil prices, oil prices spillovers, stock market, volatility, and stock returns are the main research direction, with most of the contribution coming from China, the USA, France, the UK, and Tunisia.
Table 1 Descriptive statistics

\begin{tabular}{|c|c|}
\hline Description & Results \\
\hline \multicolumn{2}{|c|}{ Main information about data } \\
\hline Timespan & 1999-2021 \\
\hline Sources (journals, books, etc.) & 182 \\
\hline Documents & 684 \\
\hline Average years from publication & 3.63 \\
\hline Average citations per document & 26.17 \\
\hline Average citations per year per doc & 4.474 \\
\hline References & 13518 \\
\hline \multicolumn{2}{|c|}{ Document contents } \\
\hline Keywords plus (ID) & 808 \\
\hline Author’s keywords (DE) & 1716 \\
\hline \multicolumn{2}{|l|}{ Authors } \\
\hline Authors & 1198 \\
\hline Author appearances & 1864 \\
\hline Authors of single-authored documents & 78 \\
\hline Authors of multi-authored documents & 1120 \\
\hline \multicolumn{2}{|c|}{ Authors collaboration } \\
\hline Single-authored documents & 93 \\
\hline Documents per author & 0.571 \\
\hline Authors per document & 1.75 \\
\hline Co-authors per documents & 2.73 \\
\hline Collaboration index & 1.9 \\
\hline
\end{tabular}

\section{Influential aspects of economic literature}

\section{Most influential research journals}

In order to analyze the impact of the most influential research journals, we use source impact and Bradford law, where Table 2 provides the list of top 10 research journals based on total publications, publication starting year, total citations, and h-index. In comparison, Table 3 ranks top 20 research journals based on classification from Bradford law, which classifies academic journals in three categories with zone 1 including core research journals to publish literature related to oil prices fluctuations and stock market returns. This is also called as a nuclear zone as it provides the most significant research contribution. We can conclude that out of 182 research journals, 5 journals in zone 1, 21 journals in zone 2 , and 156 journals lie in zone 3 .

Energy Economics is the most significant platform with a particular focus on analyzing the oil prices-stock market nexus. The most significant study in the journal was "Oil price shocks and stock market activity” (Sadorsky, 1999), which investigated how oil price volatility affects real stock market returns. On the basis of empirical analysis, the researcher claimed that since 1986, in comparison to interest rates, oil price movements have had a greater effect on stock market returns. In a similar study, "Oil price shocks 
Fig. 2. Annual publications trend

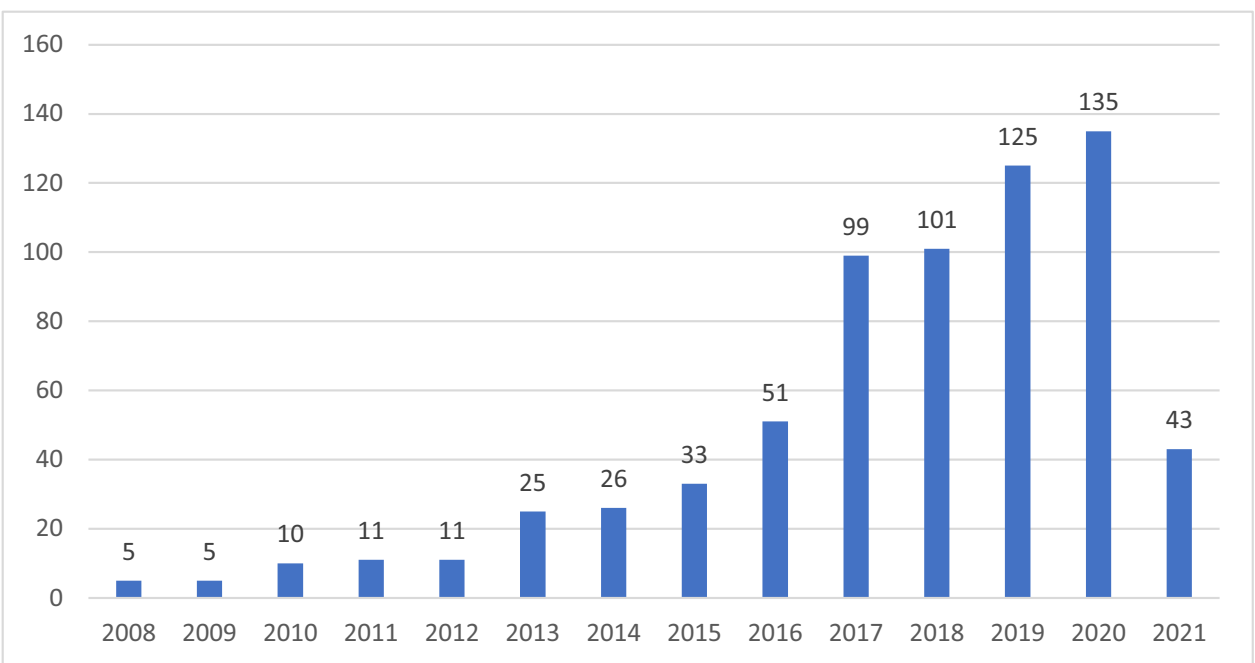

Fig. 3. Annual citations trend and stock markets in the US and 13 European countries," Park and Ratti (2008) used panel datasets from the USA and 13 countries to indicate that oil price shocks lead to $6 \%$ variance in the stock market returns, though the effect in European countries was significantly higher than the US economy. In another study, El-Sharif et al. (2005) conceptualized the effect of crude oil prices and equity values in the oil and gas sector of the UK to conclude that the association is positive and oil price variation negatively impacts share values within the energy sector. Resources Policy is the second-ranked journal with a primary focus on the oil prices volatility's impact on the emerging economies. Raza et al. (2016) investigated the asymmetric impact of oil price volatility on stock markets in emerging economies to conclude that oil prices changes lead to stock market volatility and uncertain economic conditions in BRICS, Indonesia, Chile, Thailand, Malaysia, and Mexico. Another study from Jain and Biswal (2016) investigated the association between oil price changes, USD-INR exchange rate, and the stock market in India and revealed that oil price volatility negatively affects the exchange value of Indian currency and benchmark Sensex stock index. Energy is another notable academic research journal, which has published research related to dynamism and volatility in oil and the stock markets. Liu et al. (2013) used the crude oil volatility index as a measure of oil market uncertainty during the 2008 financial crisis to research its impact on stock market returns and concluded that investors' volatility expectations in the oil market are more sensitive during the global economic crisis. In another study, Chiou and Lee (2009) not only examined the asymmetric impacts of oil price volatility over stock market returns. By using the daily dataset from S\&P 500 and WTI oil transactions from 1992 to 2006, the researchers concluded that high fluctuations in oil prices have asymmetric impacts on S\&P 500 returns.

Figure 5 reports the publication trend in top 10 scientific journals to understand research publication through time. Energy Economics has made the most significant 


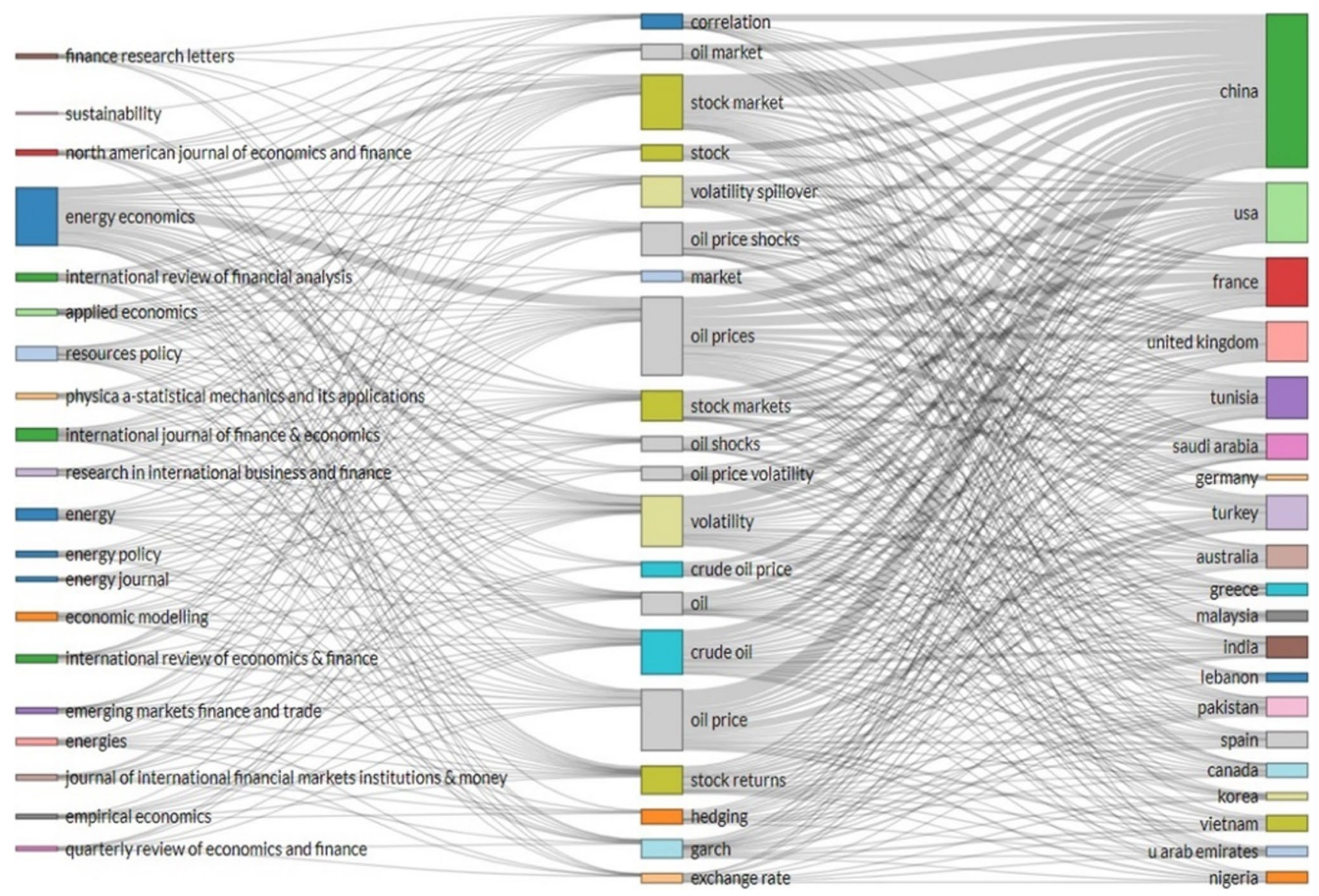

Fig. 4. Three field analyses of theoretical literature

Table 2 Top 10 journals according to source impact

\begin{tabular}{llllll}
\hline Source titles & h_index & g_index & TC & NP & PY_start \\
\hline Energy Economics & 45 & 82 & 7127 & 131 & 1999 \\
Resources Policy & 12 & 25 & 634 & 31 & 2016 \\
Energy & 15 & 25 & 777 & 25 & 2009 \\
Economic Modelling & 14 & 23 & 911 & 23 & 2011 \\
Physica A-Statistical Mechanics and its Applications & 10 & 17 & 337 & 23 & 2015 \\
International Journal of Finance \& Economics & 2 & 4 & 23 & 19 & 2020 \\
International Review of Economics \& Finance & 10 & 18 & 332 & 18 & 2013 \\
International Review of Financial Analysis & 12 & 18 & 891 & 18 & 2011 \\
Applied Economics & 9 & 16 & 371 & 16 & 2010 \\
North American Journal of Economics and Finance & 8 & 16 & 268 & 16 & 2013 \\
\hline
\end{tabular}

research contribution, but Resources Policy has made the most contribution since 2015, while Energy, Economic Modelling, and Physica A-Statistical Mechanics and its Applications also have made a steady contribution in recent years. Policymakers and academic scholars must note these scientific trends as these journals provide useful information to analyze the impact of the oil price-stock market nexus.

\section{Core research publications}

The current section provides the list of top 15 research papers in oil price-stock market literature. Table 4 includes global citations and local citations, where global citations provide overall citation analysis, while local citations provide citation statistics in the sampled literature. "Oil price shocks and stock market activity" by Sadorsky (1999) is 
Table 3 Journal rankings (Bradford law)

\begin{tabular}{lllll}
\hline Sources & Rank & Freq & cumFreq & Zone \\
\hline Energy Economics & 1 & 131 & 131 & Zone 1 \\
Resources Policy & 2 & 31 & 162 & Zone 1 \\
Energy & 3 & 25 & 187 & Zone 1 \\
Economic Modelling & 4 & 23 & 210 & Zone 1 \\
Physica A-Statistical Mechanics and its Applications & 5 & 23 & 233 & Zone 1 \\
International Journal of Finance \& Economics & 6 & 19 & 252 & Zone 2 \\
International Review of Economics \& Finance & 7 & 18 & 270 & Zone 2 \\
International Review of Financial Analysis & 8 & 18 & 288 & Zone 2 \\
Applied Economics & 9 & 16 & 304 & Zone 2 \\
North American Journal of Economics and Finance & 10 & 16 & 320 & Zone 2 \\
Energies & 11 & 15 & 335 & Zone 2 \\
Emerging Markets Finance and Trade & 12 & 14 & 349 & Zone 2 \\
Research in International Business and Finance & 13 & 13 & 362 & Zone 2 \\
Energy Policy & 14 & 12 & 374 & Zone 2 \\
Finance Research Letters & 15 & 11 & 385 & Zone 2 \\
Journal of International Financial Markets Institutions \& Money & 16 & 10 & 395 & Zone 2 \\
Quarterly Review of Economics and Finance & 17 & 8 & 403 & Zone 2 \\
Energy Journal & 18 & 7 & 410 & Zone 2 \\
Applied Energy & 19 & 6 & 416 & Zone 2 \\
Emerging Markets Review & 20 & 6 & 422 & Zone 2 \\
\hline
\end{tabular}

Fig. 5. Publication trend in top 10 journals

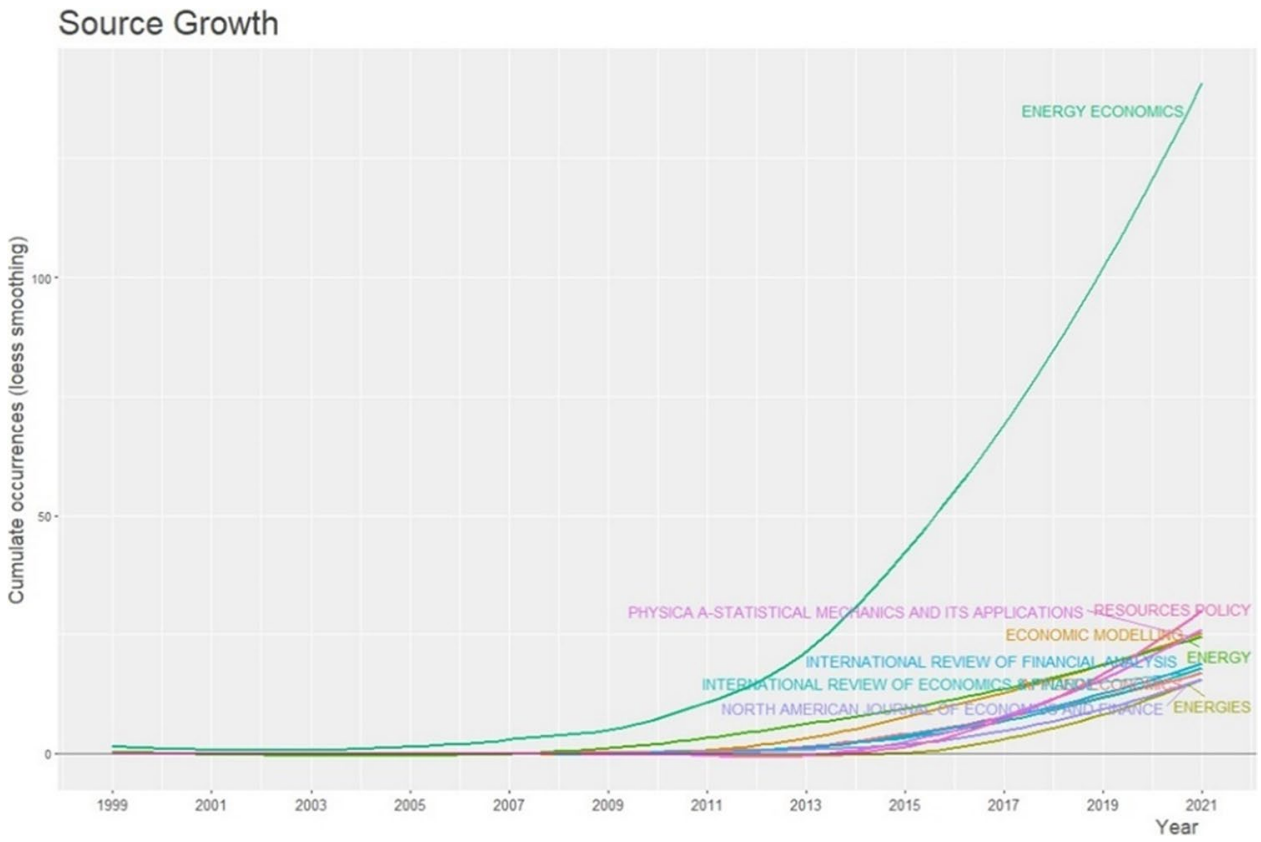

the most cited research item where the author researched oil price volatility and its correlation with real stock market returns to claim that oil price changes rather than interest rate movements have a greater effect on stock market returns. "Oil price shocks and stock markets in the US and 13 European countries" by Park and Ratti (2008) is the second most cited study where the researchers investigated a panel dataset of the USA and 13 countries to conclude that oil price changes negatively affect stock market returns, though the effect in European countries was significantly higher than the US economy. "Dynamic correlation between the stock market and oil prices: The case of oil-importing and oilexporting countries" by Filis et al. (2011) is the third-highest cited research item where researchers investigated the timevarying correlation between oil prices and stock market performance for oil exporting and importing countries. By 
Table 4 Most locally and globally cited paper

\begin{tabular}{|c|c|c|c|c|}
\hline Paper title & Corresponding author & Year & Local citations & Global citations \\
\hline Oil price shocks and stock market activity & Sadorsky, P & 1999 & 258 & 802 \\
\hline Oil price shocks and stock markets in the US and 13 European countries & Ratti, RA & 2008 & 226 & 572 \\
\hline $\begin{array}{l}\text { Dynamic correlation between stock market and oil prices: The case of oil- } \\
\text { importing and oil-exporting countries }\end{array}$ & Filis, G & 2011 & 137 & 294 \\
\hline $\begin{array}{l}\text { Relationships between oil price shocks and stock market: An empirical analysis } \\
\text { from China }\end{array}$ & Wei, Yi-Ming & 2008 & 132 & 305 \\
\hline $\begin{array}{l}\text { Volatility spillovers between oil prices and stock sector returns: Implications } \\
\text { for portfolio management }\end{array}$ & Nguyen, DK & 2011 & 106 & 286 \\
\hline $\begin{array}{l}\text { On the impacts of oil price fluctuations on European equity markets: Volatility } \\
\text { spillover and hedging effectiveness }\end{array}$ & Arouri, ME & 2012 & 103 & 199 \\
\hline $\begin{array}{l}\text { Oil price shocks and stock market activities: Evidence from oil-importing and } \\
\text { oil-exporting countries }\end{array}$ & $\mathrm{Wu}, \mathrm{CF}$ & 2013 & 97 & 208 \\
\hline $\begin{array}{l}\text { Correlations and volatility spillovers between oil prices and the stock prices of } \\
\text { clean energy and technology companies }\end{array}$ & Sadorsky, P & 2012 & 86 & 275 \\
\hline $\begin{array}{l}\text { Return and volatility transmission between world oil prices and stock markets } \\
\text { of the GCC countries }\end{array}$ & Nguyen, DK & 2011 & 84 & 166 \\
\hline $\begin{array}{l}\text { Evidence on the nature and extent of the relationship between oil prices and } \\
\text { equity values in the UK }\end{array}$ & Burton, B & 2005 & 82 & 228 \\
\hline Oil price shocks and stock market activity & Sadorsky, P & 1999 & 258 & 802 \\
\hline Oil price shocks and stock markets in the US and 13 European countries & Ratti, RA & 2008 & 226 & 572 \\
\hline $\begin{array}{l}\text { Dynamic correlation between stock market and oil prices: The case of oil- } \\
\text { importing and oil-exporting countries }\end{array}$ & Filis, G & 2011 & 137 & 294 \\
\hline $\begin{array}{l}\text { Relationships between oil price shocks and stock market: An empirical analysis } \\
\text { from China }\end{array}$ & Wei, Yi-Ming & 2008 & 132 & 305 \\
\hline $\begin{array}{l}\text { Volatility spillovers between oil prices and stock sector returns: Implications } \\
\text { for portfolio management }\end{array}$ & Nguyen, DK & 2011 & 106 & 286 \\
\hline
\end{tabular}

using DCC-GARRCH-GJR approach, the empirical findings concluded that time-varying correlation does not differ for oil exporting and oil importing countries in response to oil price shocks. Another notable study, "On the impacts of oil price fluctuations on European equity markets: Volatility spillover and hedging effectiveness" by Arouri et al. (2012), examined volatility spillover effects between stock markets returns and oil prices in Europe to indicate that volatility spillovers between stock market returns and oil prices are crucial for portfolio management strategies.

\section{Core words}

Next, we analyze the most frequent keywords in the literature, where Table 5 provides a statistical overview of keywords plus, author keywords, abstracts, and title. In all four keywords analysis, "volatility" and "returns" are the most common keywords. Meanwhile, stock markets, shocks, and oil prices are also shown in all categories. These keywords are related to the stock market-oil prices nexus as it explains stock market performance, especially in the emerging markets. In oil price-stock market literature, there is minimal use of author keywords. Keywords plus cover the basic literature which is related to volatility spillover effects from oil price volatility towards stock market returns. Oil, stock, and markets are the most frequent keywords in the abstracts and titles. Additionally, the terms in titles and abstracts are too generic and are less likely to contribute towards main research themes.

Figure 6 shows the word cloud, where a larger size indicates higher frequency. Oil prices, stock markets, and stock returns are the most frequent keywords in the sampled studies. The keywords of oil price volatility, oil shocks, and stock prices have also led to a strong research contribution in the literature as the focus is to analyze how oil price changes affect stock prices, especially in emerging economies. Finally, stock market returns, exchange rate, and investor sentiments are also frequent keywords in the literature as these studies investigate investors' responses towards shifts in exchange rate and stock market returns. In summary, all of the keywords (Fig. 6) address issues related to oil price volatility, stock market returns, and spillover effects that can follow this to improve future research output.

We further the keyword analysis by investigating the trends in the top 10 keywords in the sampled literature. As indicated in Fig. 7, the three keywords of oil prices, volatility, and stock market have significant growth since 2013 onwards as there has been significant attention towards 
Table 5 Most frequent keywords

\begin{tabular}{llll}
\hline Keywords plus & Freq. & Authors keywords & Freq. \\
Volatility & 263 & Oil prices & 85 \\
Shocks & 201 & Oil price & 72 \\
Returns & 194 & Stock market & 72 \\
Impact & 172 & Volatility & 70 \\
Crude oil & 169 & Crude oil & 49 \\
US & 145 & Stock returns & 37 \\
price shocks & 129 & Oil price shocks & 33 \\
Risk & 112 & Stock markets & 30 \\
Macroeconomy & 90 & Volatility spillover & 28 \\
Time-series & 77 & GARCH & 23 \\
Volatility spillovers & 70 & Oil & 23 \\
Stock markets & 69 & Oil shocks & 21 \\
Markets & 67 & Oil market & 18 \\
Energy & 64 & Stock & 18 \\
Uncertainty & 61 & Oil price volatility & 16 \\
Titles & Freq. & Abstracts & Freq. \\
Oil & 547 & Oil & 2953 \\
Stock & 408 & Stock & 1841 \\
Markets & 216 & Market & 1380 \\
Market & 212 & Volatility & 1256 \\
Volatility & 205 & Price & 1071 \\
Price & 191 & Markets & 930 \\
Evidence & 170 & Prices & 804 \\
Prices & 155 & Returns & 776 \\
Crude & 140 & Crude & 650 \\
Returns & 104 & Shocks & 588 \\
Shocks & 91 & Model & 500 \\
Energy & 72 & Risk & 457 \\
Risk & Financial & 433 \\
Dynamic & Paper & 422 \\
Financial & Study & 364 \\
\hline
\end{tabular}

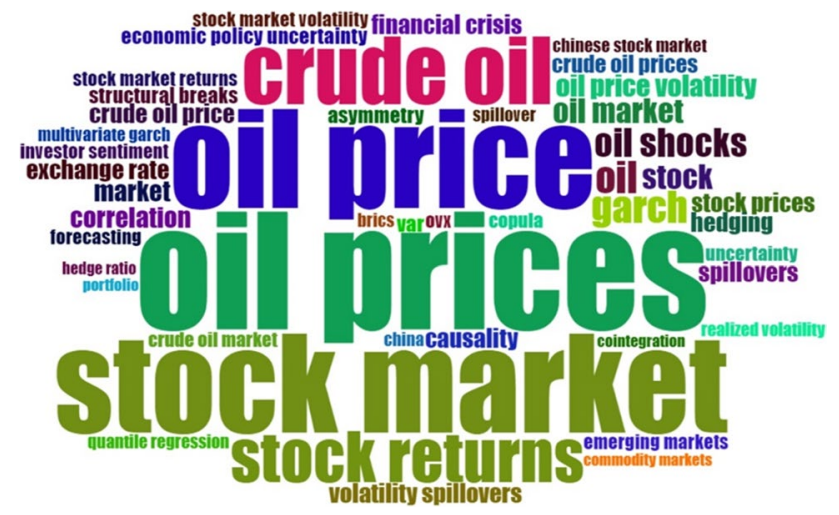

Fig. 6. Word cloud investigating the association between oil prices and stock market performance. Other keywords such as stock returns, oil prices shocks, and stock market examine how oil price movements may contribute to the volatility spillovers from oil prices towards stock returns in stock markets.

\section{Main researchers, research institutions, and countries}

The current section of the manuscript provides statistical information about researchers, academic affiliation, research institutions, and countries with the most research contribution. Table 6 provides the top 10 researchers ranked on the criteria of total publications and h-index. With the highest publications and h-index, Hammoudeh is the most influential author and focused on the oil price-macroeconomic fundamentals nexus in emerging markets. "Do global factors impact BRICS stock markets? A quantile regression approach" is the highest cited publication by Hammoudeh, which investigated the dependence structure between global macroeconomic factors and their impact over emerging stock markets of BRICS. Bouri is the second author in total publications with a research focus on return and volatility linkages between oil prices and stock markets in emerging economies. The study titled "The directional volatility connectedness between crude oil and equity markets: New evidence from implied volatility indexes" by Bouri concluded that changes in oil prices have a greater effect on stock market performance than the other way around. Shahzad SJH is the third-ranked author with research publications analyzing time-varying causality between stock market returns and oil prices changes. The most cited publication by Shahzad SJH "Modeling systemic risk and dependence structure between oil and stock markets using a variational mode decomposition-based copula method" investigated the combined the time-varying symmetric and asymmetric copula and variational mode decomposition functions to indicate the existence of tail dependence between stock market returns and crude oil prices. Tiwari AK is the fourth-ranked author with research interests in connectedness among commodity prices, stock market indexes, and crude oil prices. The most cited research publication by the Tiwari, "Asymmetric impact of gold, oil prices and their volatilities on stock prices of emerging markets," indicated that oil prices changes have negative, while gold prices have a positive impact over the performance of emerging stock markets. Filis $\mathrm{G}$ is the fifthranked author with a research background in dynamic comovements between policy uncertainty, implied volatility, and stock market returns. The most cited publication by Filis is "Dynamic correlation between the stock market and oil prices: The case of oil-importing and oil-exporting countries" suggested that oil prices exercise a negative effect in all stock markets, regardless the origin of the oil price shock. 
Fig. 7 Keyword growth overtime

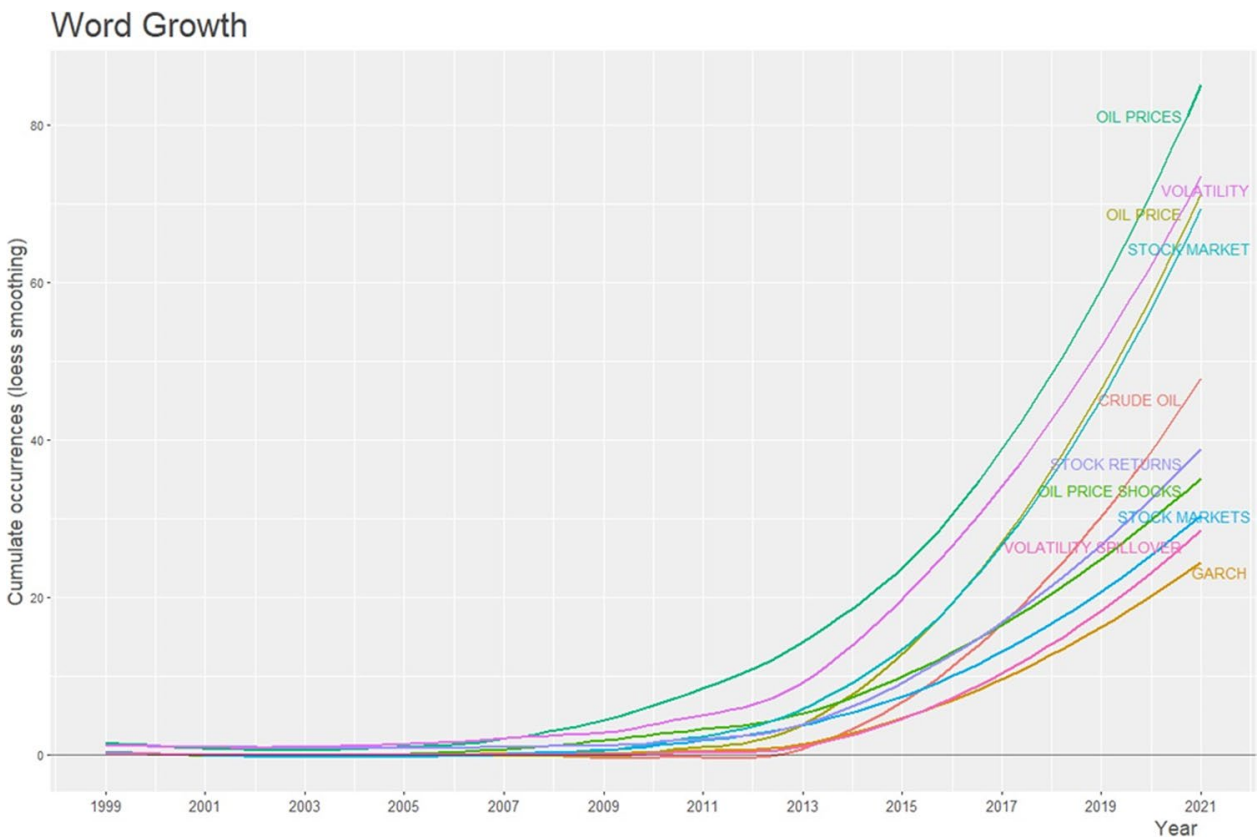

Table 6 Top 10 authors

\begin{tabular}{lllll}
\hline Authors & h-index & TC & TP & PY-Start \\
\hline Hammoudeh S & 15 & 1018 & 21 & 2010 \\
Bouri E & 12 & 652 & 20 & 2015 \\
Shahzad SJH & 11 & 558 & 15 & 2016 \\
Tiwari AK & 9 & 255 & 14 & 2016 \\
Filis G & 10 & 948 & 13 & 2010 \\
Guesmi K & 4 & 180 & 12 & 2014 \\
Mensi W & 9 & 788 & 12 & 2013 \\
Wang YD & 10 & 483 & 12 & 2013 \\
Nguyen DK & 10 & 1118 & 11 & 2011 \\
Dutta A & 7 & 206 & 10 & 2017 \\
\hline
\end{tabular}

Table 7 Countries with most publications and citations

\begin{tabular}{llll}
\hline Countries/regions & $\begin{array}{l}\text { Most pub- } \\
\text { lications }\end{array}$ & Countries/regions & Most citations \\
\hline China & 387 & China & 4311 \\
USA & 151 & USA & 2316 \\
France & 137 & France & 1991 \\
UK & 88 & Canada & 1497 \\
Tunisia & 76 & UK & 1465 \\
Turkey & 70 & Australia & 882 \\
India & 58 & India & 640 \\
Australia & 57 & Tunisia & 423 \\
Saudi Arabia & 48 & Lebanon & 417 \\
Pakistan & 42 & UAE & 356 \\
\hline
\end{tabular}

Next, Table 7 provides statistical information about the research contribution of the top 10 countries. We divide the research information into two sections: where the left side of the table lists countries on the basis of research publications, while on the right, we rank countries on the basis of most citations. China, the USA, France, the UK, Australia, India, and Tunisia have the most consistent impact on academic research as they appear in both lists. Meanwhile, Saudi Arabia and Pakistan are ranked 9th and 10th in total publications only; and Lebanon and UAE are also 9th and 10th in the list of most citations only.

We further the research by examining the impact of research institutions. IPAG Business School is ranked first with 28 academic publications, followed by Montpellier Business School and Drexel University with 26 and 21 research papers, respectively. Further examination indicates that top 10 research institutions have focused on asymmetric responses of sectoral equities to oil price shocks, risk spillovers, and portfolio management as research contribution is closely associated in terms of total publications and research collaboration (Fig. 8).

Table 8 provides detailed information regarding the top 10 countries by dividing statistical information into singleauthored publications (SCP) and multi-authored publications (MCP). China is ranked first with 174 publications, where 123 publications are single-authored and 51 publications are multi-authored papers. The USA, France, the UK, and India are ranked 2nd, 3rd, 4th, and 5th with 66, 42, 31, and 29 research papers. The USA, the UK, and Saudi Arabia are the only countries in the top 10 countries which has 
Fig. 8. Most relevant research institutions

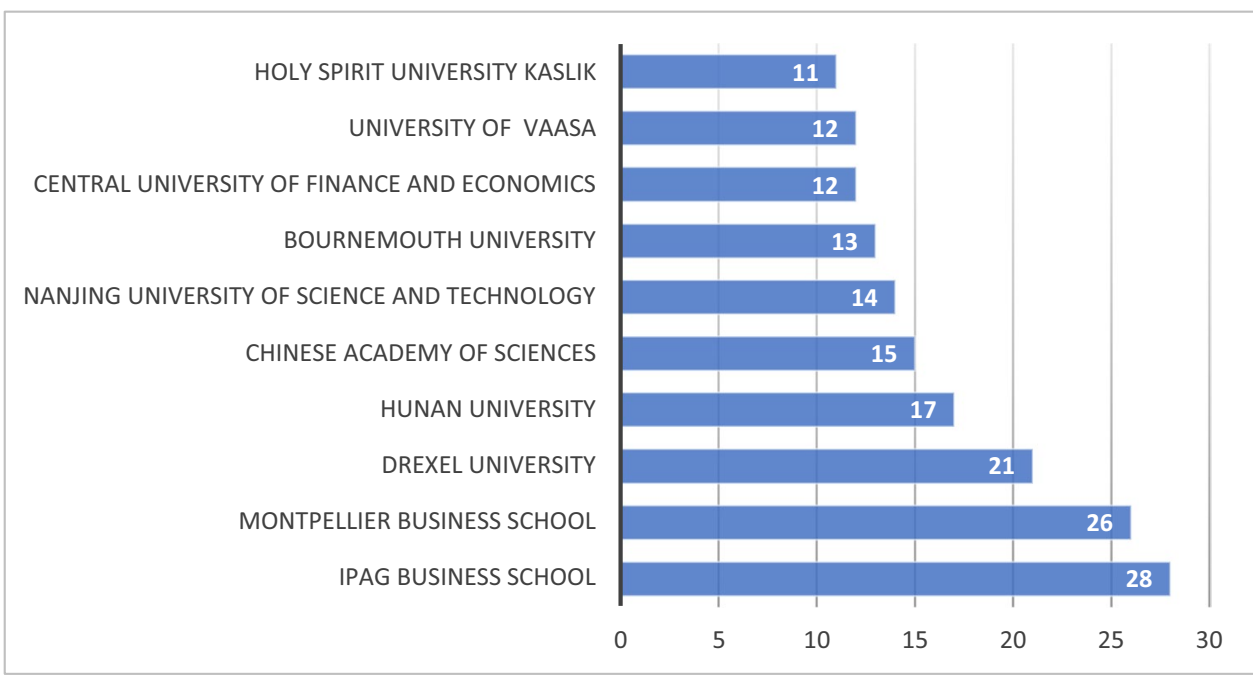

Table 8 List of countries (most corresponding authors)

\begin{tabular}{llllll}
\hline Country & Articles & Freq & SCP & MCP & MCP_Ratio \\
\hline China & 174 & 0.25476 & 123 & 51 & 0.293 \\
USA & 66 & 0.09663 & 28 & 38 & 0.576 \\
France & 42 & 0.06149 & 16 & 26 & 0.619 \\
UK & 31 & 0.04539 & 12 & 19 & 0.613 \\
India & 29 & 0.04246 & 26 & 3 & 0.103 \\
Turkey & 28 & 0.041 & 22 & 6 & 0.214 \\
Australia & 26 & 0.03807 & 15 & 11 & 0.423 \\
Tunisia & 20 & 0.02928 & 14 & 6 & 0.3 \\
South Korea & 16 & 0.02343 & 7 & 9 & 0.562 \\
Saudi Arabia & 15 & 0.02196 & 7 & 8 & 0.533 \\
\hline
\end{tabular}

Table 9 Collaboration network

\begin{tabular}{lll}
\hline From & To & Frequency \\
\hline France & Tunisia & 26 \\
France & USA & 22 \\
China & USA & 20 \\
Tunisia & Saudi Arabia & 19 \\
China & France & 14 \\
France & Saudi Arabia & 14 \\
China & UK & 13 \\
France & Pakistan & 13 \\
Greece & UK & 11 \\
USA & Turkey & 11 \\
\hline
\end{tabular}

produced more MCP than SCP, which shows that degree of research collaboration is higher in these countries, though Saudi Arabia has the least research output.

The issue of oil price-stock market performance is one of the most critical issues in the modern economic literature, which is why higher cross-border research collaboration is critical in overcoming limitations in the current literature. Table 9 addresses this issue by highlighting research collaboration at the country level. France and Tunisia have contributed most with 26 joint research projects followed by France and the USA and China and the USA with 22 and 20 publications each, respectively. China, the USA, and France are responsible for the highest academic and scientific collaboration in the scientific literature (Fig. 9).

\section{Conceptual framework}

In the current section, we analyze the various research streams in the selected studies. For these, we devise a conceptual framework consisting of co-occurrence network analysis and a bi-dimensional matrix "thematic map" to examine the density and centrality of the network analysis.

\section{Co-citation analysis}

We begin our conceptual framework by analyzing cocitation analysis (Fig. 10), which is defined as the "the number of times two articles are cited together" (Small, 1973). Co-citation analysis helps examine the intellectual structure during a systematic literature review to reveal the developments and research structure of current literature (Rossetto et al. 2018). In the co-citation analysis, the cooccurrence of two articles as citations is represented by nodes. We consider two articles belong to similar subject matter if they are jointly cited in a research publication (Hjørland, 2013). Previous literature has used clustering as an analytical measure to examine research publications (Radicchi et al. 2004) and identify the research patterns (Xu et al. 2018). 


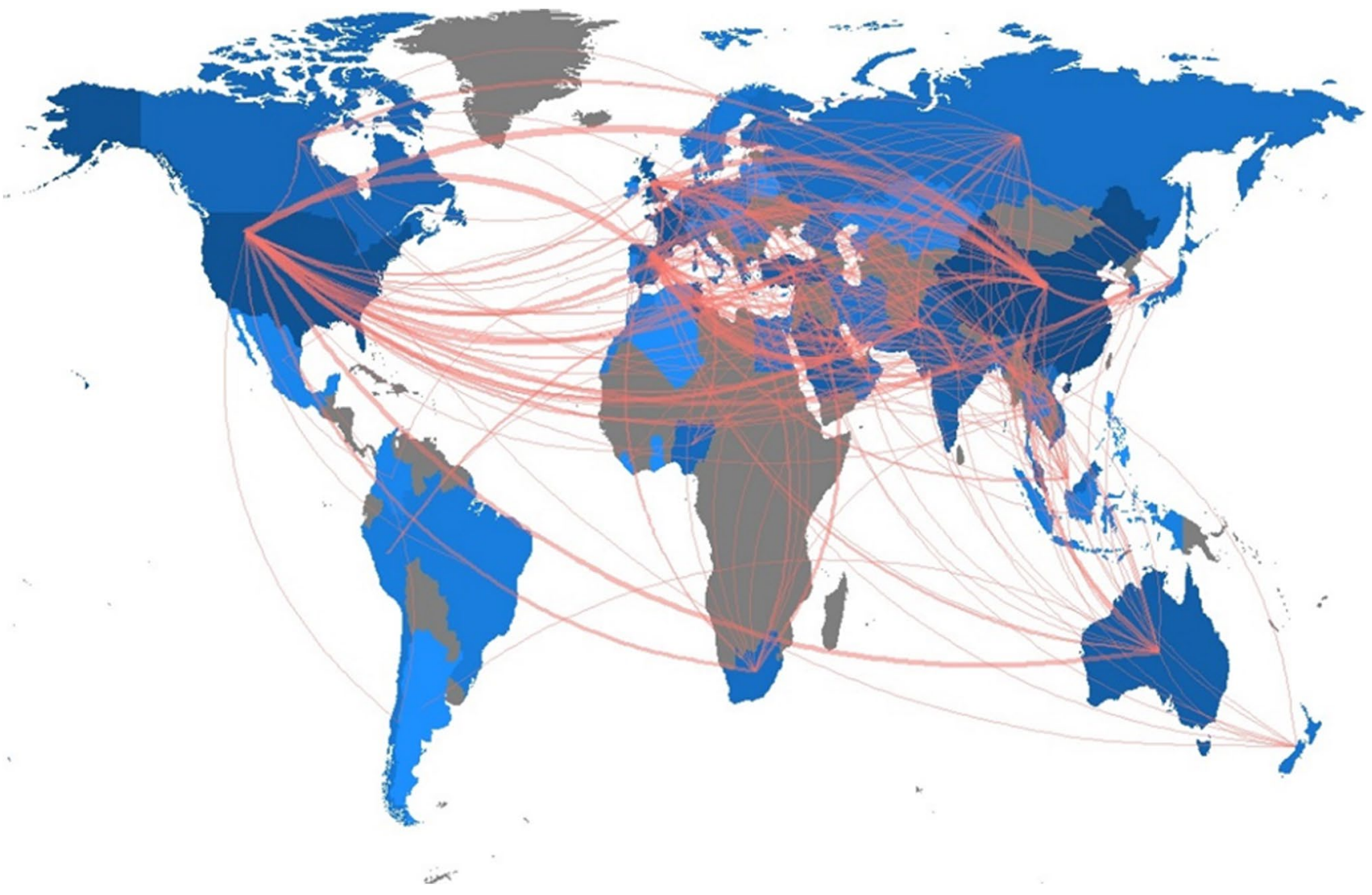

Fig. 9. Countries with most research collaboration

\section{Content analysis}

The co-citation analysis classifies current research into three distinct clusters. The current section provides a detailed overview of the research theme in each cluster. To identify the research theme, we selected top 10 research papers in every cluster, which is common in systematic and bibliometric analysis (Fahimnia et al. 2015).

Cluster 1 (red): oil price shocks, stock market activity, and the emerging economies Cluster 1 is the largest of the three clusters, which primarily discusses the association between oil price changes, stock market response, and emerging economies and expanded the research horizon by investigating how these changes impact financial markets (Ciner, 2001; Huang et al. 1996) and equity prices (Nandha \& Faff, 2008) and how such changes can push financial markets into bear activity (Chen, 2010). Lastly, another subcomponent in cluster 1 explored how oil price shocks in emerging economies affect macroeconomic conditions (Papapetrou, 2001), exchange rates (Basher et al. 2012), and market stability (Miller \& Ratti, 2009).
Cluster 2 (blue): oil volatility behavior and spillover effects in oil exporting and importing countries Cluster 2 is the second largest cluster which primarily investigated how oil price shocks are responsible for volatility behavior in oil exporting and importing countries. The primary motivation is to identify the exact nature of the dynamic correlation between volatility behavior between oil prices and stock markets (Filis et al. 2011), nonlinear modeling (Arouri et al. 2012), and shock and volatility transmissions (Malik \& Hammoudeh, 2007). Another group of researchers explored spillover effects from oil price volatility with the main research direction towards equity returns (Arouri et al. 2011) and stock market returns in the long run (Choi \& Hammoudeh, 2010).

Cluster 3 (green): oil prices, stock market returns, and portfolio management Cluster 3 is the smallest cluster, which focuses on oil prices, stock market returns, and portfolio management (Arouri \& Nguyen, 2010); risk factors towards investment in oil and gas companies (Boyer \& Filion, 2007); firm returns (Narayan \& Sharma, 2011); stock market booms (Bjørnland, 2009); and alternative energy companies 
Fig. 10 Co-citation analysis

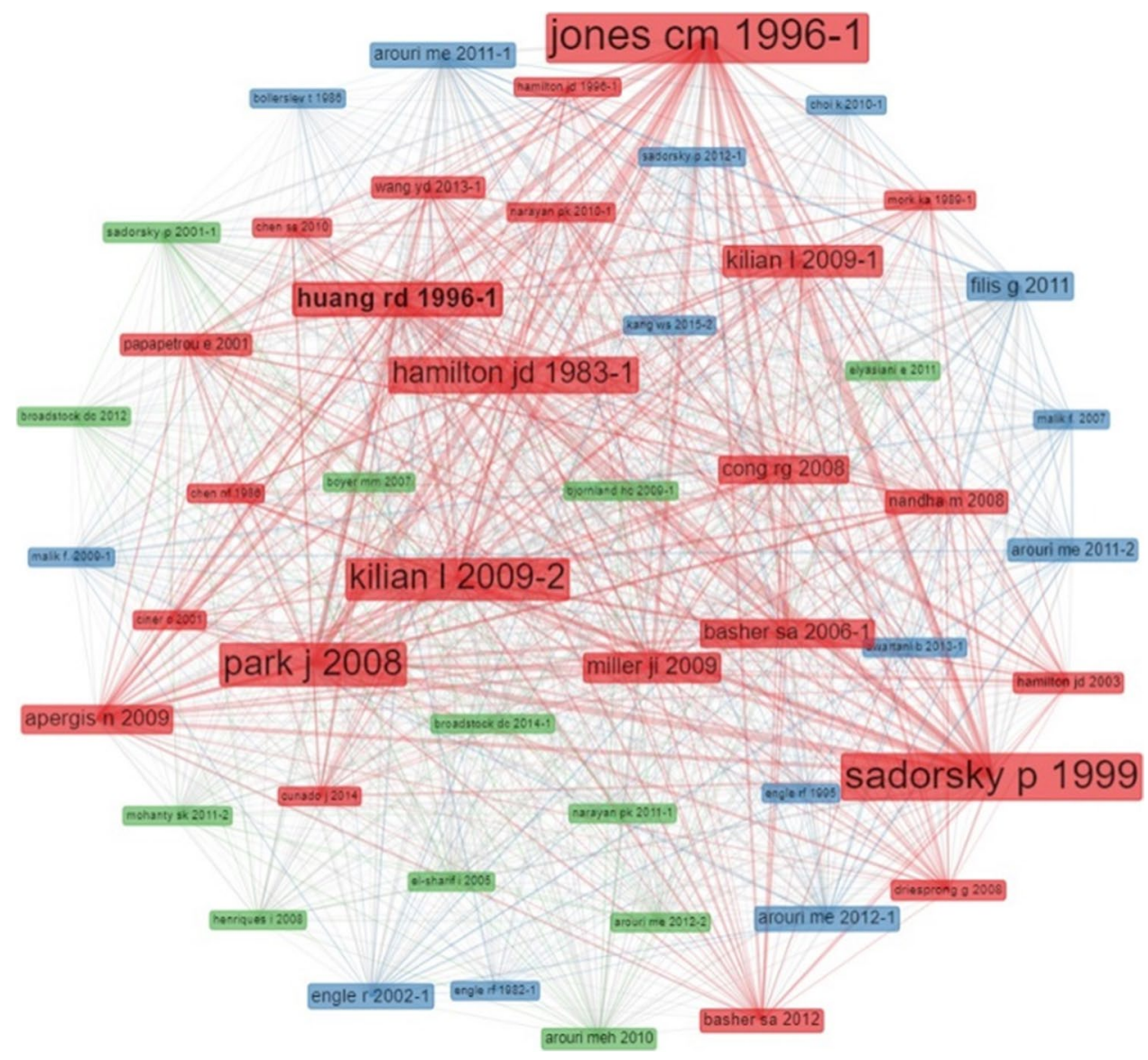

(Henriques \& Sadorsky, 2008). These indicators describe how changes in oil price shock affect stock returns and portfolio investment strategies, which is essential in explaining the interaction between oil price changes and investor decisions in the long run.

\section{Co-occurrence network}

Figure 10 shows a co-occurrence network, where the cooccurrence network can be classified into four research streams. Blue cluster has the high centrality and investigates the impact of oil price shocks, stock market returns, and emerging economies with a key focus on introducing policy mechanisms to hedge against negative macroeconomic implications from oil price shocks. The red cluster addresses the link between oil prices, stock market volatility, and macroeconomic implications. In recent times, there has been a higher emphasis on oil-importing economies to forecast the implications of stock market returns, exchange rate, and financial uncertainty. The magenta cluster is classified as oil price volatility and portfolio management strategies. This cluster covers portfolio management strategies to create a balancing approach and avoid negative implications towards stock market investments. The green cluster is isolated and is related to how oil price shocks lead to spillover effects on the stock market; both of these factors are critical as they not only oversee stock market performance but also integrate oil price changes with macroeconomic policies as well (Table 10).

\section{Thematic map}

To further analyze the research trends, we use the thematic map to understand the development of research themes in current literature. Figure 11 represents the graphical representation of research themes based on centrality (x-axis) and the significance of research themes and density (y-axis) to analyze the development of the selected research theme. The thematic map can be divided into four sub-components. The lower left part of the thematic map contains declining or emerging themes, which can drop from the research area or become the focus of higher research interest. The lower right section illustrates transversal or basic themes, which report high centrality but low density. This research needs further research attention. The upper left section has low centrality but high density, which implies that these research topics are isolated but highly developed research areas. Finally, the upper right contains high centrality and high density. These 
Table 10 Co-occurrence network: keywords in each cluster

Fig. 11. Co-occurrence network
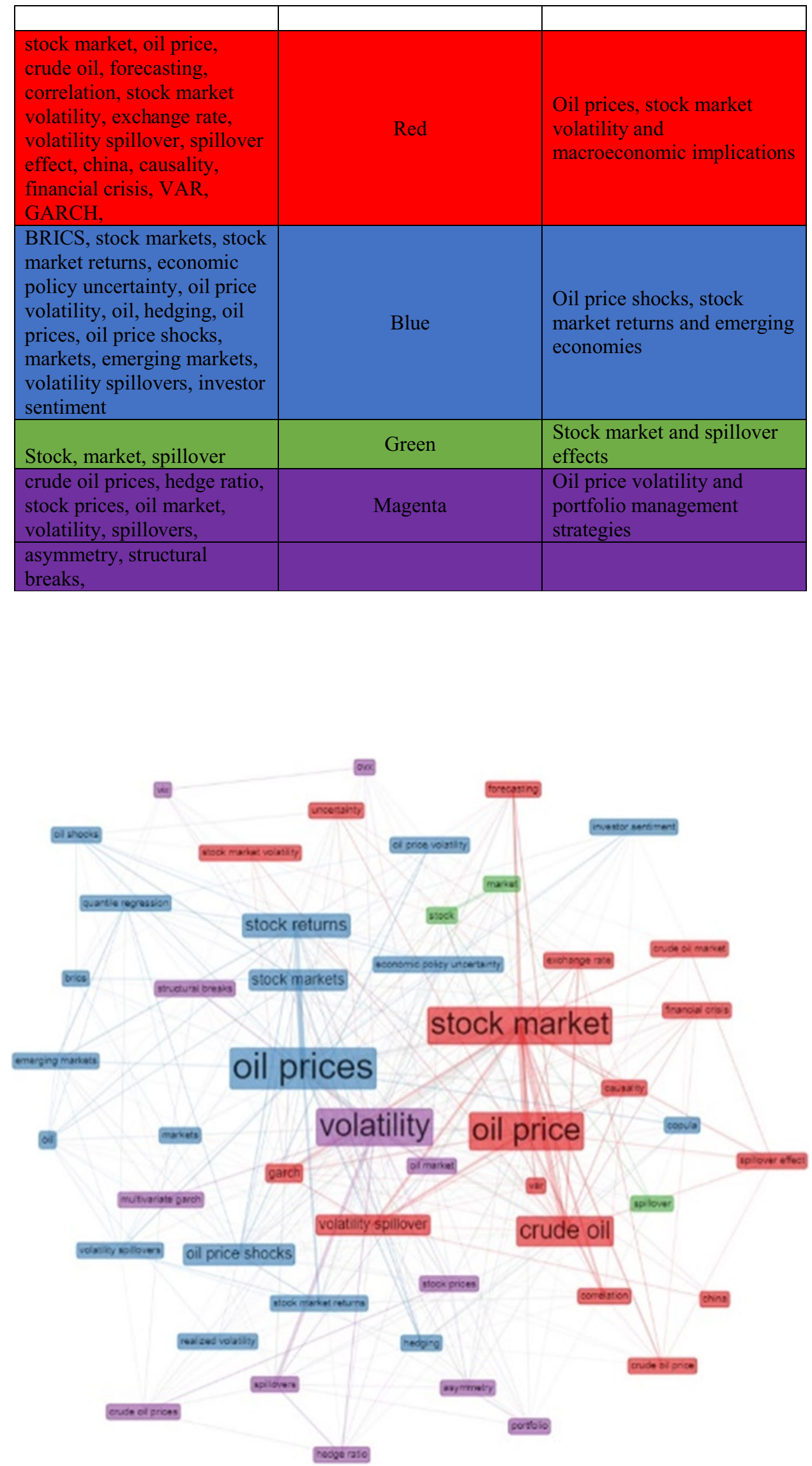
Fig. 12. Thematic map

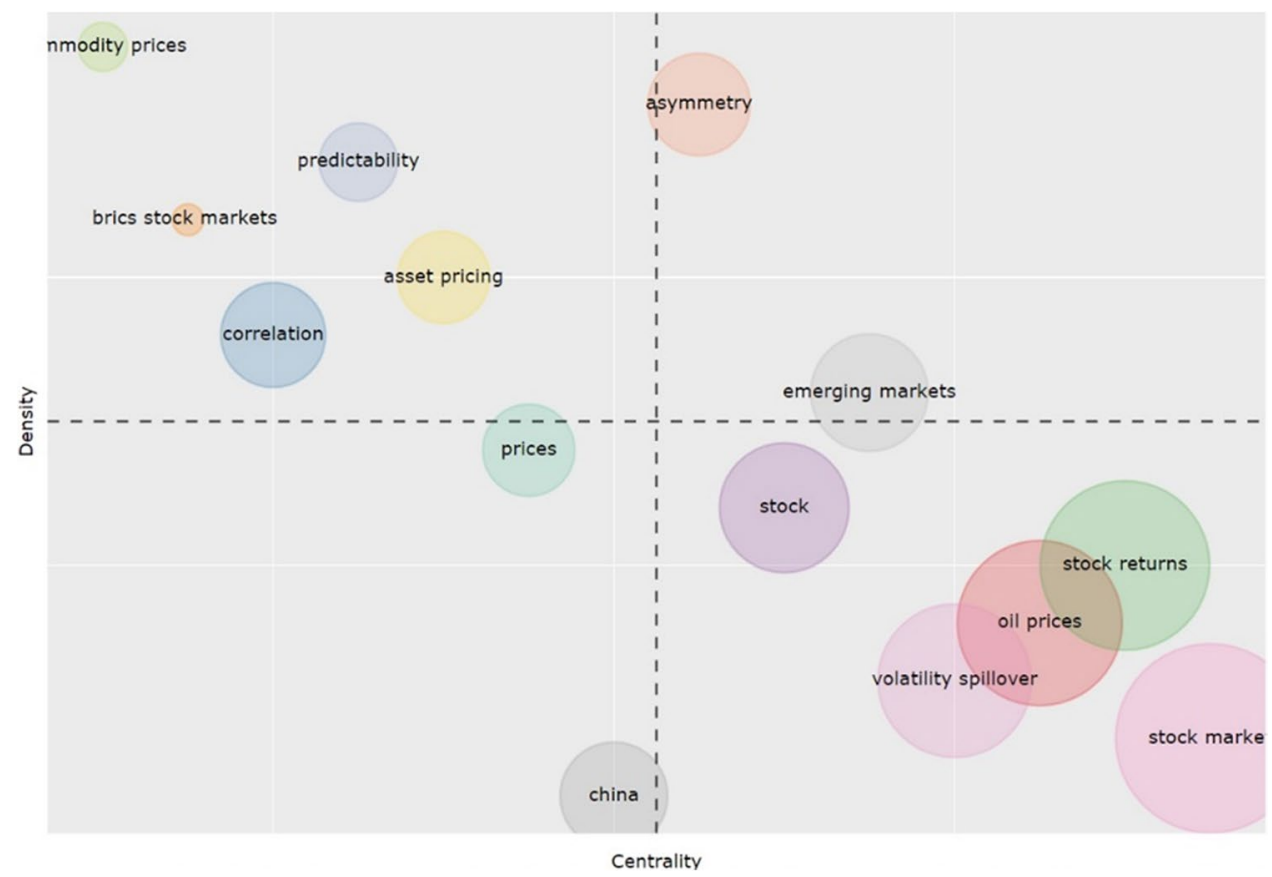

themes are termed motor themes as they are essential and highly developed research areas. We have used a minimum frequency of 5 in "biblioshiny" software and the representation label in each theme is set to 3 . We would like to clarify that it has no association with existing literature, but it represents the subjective judgment of authors keeping in view the best representation and basic dynamics of sampled dataset.

The lower right section of Fig. 12 is represented by basic themes and enlists five major research clusters. These research areas are considered transversal or basic themes due to low density and high centrality. These research areas have produced significant research contributions; hence, it becomes difficult to find future research direction because of extensive coverage in the literature. The major research theme in this cluster includes the stock market, with particular emphasis on analyzing how oil price shocks affect the stock market (Degiannakis et al. 2018). Another significant research area is "stock," where research has evaluated the impact of oil price risks can affect stock market returns and commodity trade in industrial and emerging economies alike (Arouri et al. 2011). Last, the most significant research trend evaluates the interaction between oil prices, stock returns, and volatility spillovers with a particular focus on oil price shocks, stock returns, volatility spillovers, and portfolio management to mitigate the adverse impacts from changes in oil prices. Such discussion allows investors and policymakers to balance oil price shocks and economic goals (Degiannakis et al. 2018; Sharifet al. 2020).

Next, researchers have analyzed the emerging themes from the standpoint of prices and China to evaluate how sudden shocks in oil prices can affect emerging economies such as China, with particular emphasis on the global financial crisis, energy markets, and commodity futures (Bouri, 2015). Moving forward, motor themes are considered as highly contributory themes because of high density and high centrality. In current literature, asymmetry and emerging markets represent motor themes and provide research contribution from the perspectives of economic significance, emerging markets systematic risk from oil shocks, and international crude oil price (Cabeza-García et al. 2018). Lastly, the research themes related to commodity prices, predictability, BRICS stock markets, asset pricing, and correlation are isolated yet highly developed because of low centrality and high density. These research areas are thought to have higher research potential and can lead to a significant impact on the scientific literature. Furthermore, research in subsections of highly developed and isolated themes can lead to significant changes in existing research as these themes focus on commodity prices, predictability of oil price shocks, time-varying effects, asset pricing, structural breaks, hedging strategies, and financial markets (Lin \& Su, 2020) (Table 11).

\section{Thematic evolution}

In addition, we further our analytical approach by investigating the evolution of different themes (Fig. 13). We use Bibliometrix R package and "biblioshiny" to highlight the evolution of economic literature and history of themes using two segments of time, which are based on the subjective judgment of authors to report thematic evolution during the publication time-span of economic literature. 
Table 11 Thematic maps: keywords and themes

\begin{tabular}{|c|c|c|}
\hline Main indicators & Theme & Keywords' frequency \\
\hline Asymmetry & Motor theme & $\begin{array}{l}\text { Asymmetry (12), Granger causality (7), EGARCH (6), nonlinearity (5), eco- } \\
\text { nomic significance ( } 3 \text { ) }\end{array}$ \\
\hline Emerging markets & Motor theme & $\begin{array}{l}\text { Emerging markets (11), commodities (8), decomposition (6), variance (5), Sys- } \\
\text { tematic risk (3), herding (3), international crude oil price (3) }\end{array}$ \\
\hline Commodity prices & Highly developed and isolated themes & Commodity prices (4) \\
\hline Predictability & Highly developed and isolated themes & Predictability (6), time-varying (5), dynamic model (4) \\
\hline BRICS stock markets & Highly developed and isolated themes & BRICS stock markets (4) \\
\hline Asset pricing & Highly developed and isolated themes & Asset pricing (5), structural break (5), leverage effect (4), hedging strategies (3) \\
\hline Correlation & Highly developed and isolated themes & Correlation (15), dynamic conditional (8), financial markets (8), COVID-19 (7) \\
\hline Prices & Emerging theme & Prices (7), global financial crisis (7), Islamic finance (4), energy market (4) \\
\hline China & Emerging theme & $\begin{array}{l}\text { China (10), co-movement ( } 7) \text {, renewable energy (7), commodity futures (4), } \\
\text { equity markets (3), energy stocks ( } 3 \text { ) }\end{array}$ \\
\hline Stock & Basic theme & Stock (18), market (15), structural breaks (12), spillover (10), oil price risk (6) \\
\hline Stock returns & Basic theme & $\begin{array}{l}\text { Stock returns (37), oil price shocks (33), oil (23), oil shocks (21), oil price vola- } \\
\text { tility (16), economic policy uncertainty (12), Chinese stock market (10) }\end{array}$ \\
\hline Oil prices & Basic theme & $\begin{array}{l}\text { Oil prices (85), stock markets (30), hedging (14), volatility spillovers (!4), stock } \\
\text { market returns (11) }\end{array}$ \\
\hline Volatility spillover & Basic theme & $\begin{array}{l}\text { Volatility spillover (28), oil market (18), stock prices (14), spillovers (14), stock } \\
\text { market volatility (11) }\end{array}$ \\
\hline Stock market & Basic theme & $\begin{array}{l}\text { Stock market (72), oil price (71), volatility (70), crude oil (49), GARCH (23), } \\
\text { financial crisis (14) }\end{array}$ \\
\hline
\end{tabular}

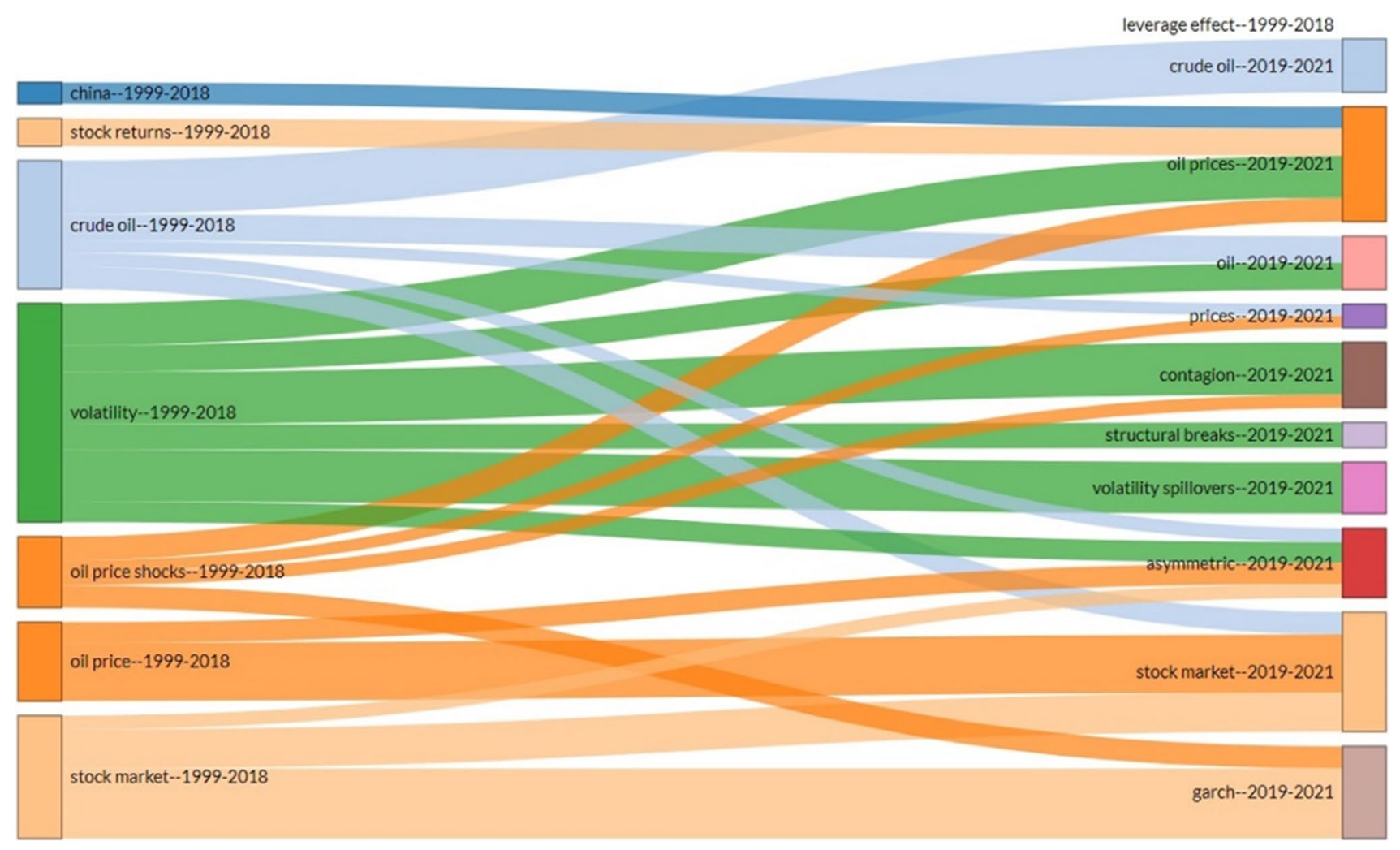

Fig. 13. Thematic evolution 
The main research segments range from 1999 to 2018 and 2019-2021, respectively. Our analysis indicates that research themes have evolved over the course of time. In the first major academic interest, "crude oil" has mainly evolved into "asymmetric impacts" and "stock markets." The next major research themes of "volatility" have evolved into oil prices, structural breaks, volatility spillovers, and asymmetric impacts as the current research not only evaluates the volatility in oil prices but how can it have broader financial and economic implications, where further focus on corporate and financial legislation is critical to overcoming negative impacts of oil prices fluctuations. Next, "oil prices" and "oil price shocks" have transformed into asymmetric impact, stock market, and GARCH. This is of great significance as the oil price shocks can have a significant impact on the stock market and expected returns from investment in stock markets. Our last thematic map primarily focuses on "stock market," which has integrated the research into GARCH, asymmetric impacts, and stock markets. This is supported by current literature as recent studies argue that future research must address the sudden and unexpected impacts of oil price shocks and how it affects investment strategies, especially in the short-run.

\section{Research questions and main findings}

The current section highlights the findings of RQs and helps provide suggestions for further research to overcome research gaps in the existing literature. The descriptive statistics and publication trends provide information about publication trends on oil price shocks and stock market returns (RQ1). Energy Economics has published most research (RQ2), which investigated how oil prices and oil prices volatility affects real stock market returns. A significant portion of studies has analyzed the ability of oil price movements towards stock market returns in industrial economies such as the USA, the UK, and European Union. Our analysis also indicates that current research is shaped by a limited number of studies (RQ3), where Sadorsky (1999) has authored the most cited research publication, followed by Park and Ratti (2008) and Filis et al. (2011). Next, keyword analysis helps us understand the rationale behind key research investigations (RQ4), where volatility and oil price shocks are the most repeated keywords in the existing literature. Furthermore, Hammoudeh has provided the most literature (RQ5) with the highest research collaboration exists between France and Tunisia, and France and USA (RQ6).

Co-citation (co-citation and content analysis) and cooccurrence network help us understand the intellectual structure in the existing literature (RQ7 and RQ8); we also use content analysis to identify three main clusters within our publications (RQ7). Cluster one identifies the association between oil price shocks, stock market activity, and the emerging economies; cluster two highlights the association between Oil volatility behavior and spillover effects in oil-exporting and importing countries; while cluster three articulates the relationship between oil prices, stock market returns, and portfolio management. Additionally, we utilize a co-occurrence network to identify four main subgroups (oil prices, stock market volatility, and macroeconomic implications; oil price shocks, stock market returns, and emerging economies; stock market and spillover effects and oil price volatility and portfolio management strategies) within the most frequent keywords.

Next, we examined the prevailing research themes in the current literature and their transformation into new research initiatives (RQ9). We have identified that over the course of time, research into oil price shocks and stock market returns has evolved into structural breaks, volatility spillovers, asymmetric association, and leverage effects. Finally, lack of theoretical development, data availability, academic collaboration, and cross-industry studies impede the current literature (RQ10 and 11), and there is a need for further research to increase academic attention and overcome limitations in the existing theoretical and empirical framework.

\section{Future research direction}

Following a thorough systematic and bibliometric analytical review, we can conclude that numerous factors hinder the existing research, and future research can overcome these limitations. The scope and extent of the current study were limited to the elements and methodology used. First, we collected literature from the only Web of Science database and excluded other relevant databases, i.e., Scopus. We estimate that the inclusion of additional databases will increase the robustness of findings from future studies. Second, we excluded non-English publications. We would encourage the researchers to widen the scope by including studies in other languages, this would also help us to formulate policy frameworks at the local level. Third, future research must be devoted towards developing a robust theoretical framework to overcome limitations in the existing literature. Fourth, as oil price shocks can carry a significant impact on global economic policies, why is why there is need to integrate research at the institutional level so that the correlation of oil price changes with macroeconomic conditions can be better interpreted. Lastly, a number of researchers have generalized the impact of oil price-stock market association across sectors on the basis of multi-industry sectors. As macroeconomic conditions differ significantly from one industry to another, hence, studies on cross-industry variation are crucial to better understand how the impact of oil price shocks differs across industries. 


\section{Conclusion}

The current study aims to deepen the understanding of the academic publications related to oil price shocks, stock market returns, and spillover effects. We provide significant insights through bibliometric literature analysis on scientific publications during the 1999-2020 period. The primary analysis was conducted to identify prevalent research trends in the existing literature. We further outline the most prestigious and influential studies, which have a significant contribution in the development of theoretical and empirical literature. Co-occurrence and keyword analysis highlight that oil price shocks, stock returns, and volatility spillover are the most significant terms in the current literature. Also, co-citation analysis divides literature into three clusters to help understand the moderating and mediating impact of different variables and how they interact with oil price shocks, stock market return, and spillover effects.

Our research makes a significant research contribution to the existing literature. First, the publication trend allowed us to examine the research contribution from institutional, author, and country levels. Second, co-authorship and mapping citations identify most co-authored networks and researchers. Third, the intellectual structure and most prominent research themes are investigated through cocitation and co-occurrence networks to identify new research directions. Fourth, we categorize factors that impede the research in oil price shocks, stock market returns, and spillover effects. Lastly, we identify limitations in the current literature to identify under-researched topics to promote further research.

Although, the current systematic and bibliometric review provides a clear picture of research trends. However, we would like to encourage the researchers to broaden the research horizon and provide policy suggestions regarding scientific contributions. First, the response to oil price variations varies across the different stock markets as well as different economic sectors. Hence, we would encourage researchers to investigate disaggregated sectoral analysis to provide additional insights in the economic literature. Second, meta-analysis is an interesting research approach that helps in summarizing current research and increases the quality of research findings by the inclusion of moderator analysis across multiple studies. In view of increased research focus on oil price shocks and stock market returns, we expect that future research will contribute in this regard.

Availability of data and materials Data and relevant materials will be available from the corresponding author through email.

Author contribution Muhammad Farhan Bashir: conceptualization, methodology, writing the original draft, data analysis, and revision

\section{Declarations}

Ethics approval Not applicable.

Consent to participate Not applicable.

Consent for publication Not applicable.

Competing interests The author declares no competing interests.

\section{References}

Arouri ME, Bellalah M, Lahiani A, and Nguyen D (2011). Oil price fluctuations and equity returns in net oil-exporting countries. Paper presented at the 6th International Finance Conference on Financial Crisis and Governance.

Arouri MEH, Jouini J, Nguyen DK (2012) On the impacts of oil price fluctuations on European equity markets: volatility spillover and hedging effectiveness. Energy Econ 34(2):611-617

Arouri MEH, Nguyen DK (2010) Oil prices, stock markets and portfolio investment: evidence from sector analysis in Europe over the last decade. Energy Policy 38(8):4528-4539

Asteriou D, Bashmakova Y (2013) Assessing the impact of oil returns on emerging stock markets: a panel data approach for ten Central and Eastern European Countries. Energy Econ 38:204-211

Asteriou D, Dimitras A, Lendewig A (2013) The influence of oil prices on stock market returns: empirical evidence from oil exporting and oil importing countries. Int J Bus Manag 8(18):101

Basher SA, Haug AA, Sadorsky P (2012) Oil prices, exchange rates and emerging stock markets. Energy Econ 34(1):227-240

Bashir MF, Shahzad U, Latif S, Bashir M (2015) The nexus between economic indicators and economic growth in Brazil. Nexus 13(1)

Bashir MF, MA B, Shahbaz M, Jiao Z (2020) The nexus between environmental tax and carbon emissions with the roles of environmental technology and financial development. PLoS ONE 15(11):e0242412. https://doi.org/10.1371/journal.pone.0242412

Bashir MF, MA B, Shahbaz M, Shahzad U, Vo XV (2021d) Unveiling the heterogeneous impacts of environmental taxes on energy consumption and energy intensity: empirical evidence from OECD countries. Energy 226:120366. https://doi.org/10.1016/j.energy. 2021.120366

Bashir MF, Ma B, Bashir MA, Radulescu M, Shahzad U (2021e) Investigating the role of environmental taxes and regulations for renewable energy consumption: evidence from developed economies. Economic Research-Ekonomska Istraživanja 1-23. https://doi.org/ 10.1080/1331677X.2021.1962383

Bashir MF, MA B, Shahzad L, Liu B, Ruan Q (2021a) China's quest for economic dominance and energy consumption: can. Asian Econ Nat Res Succ One Belt One Road? Manager Dec Econ, 2021. 42(3):570-587. https://doi.org/10.1002/mde.3255

Bashir MA, Sheng B, Farooq MU, Bashir MF, Shahzad U (2021f) The role of macroeconomic and institutional factors in foreign direct investment and economic growth: empirical evidence in the context of emerging economies. Global Local Econ Rev 24(2):67

Bashir MF, MA B, Bilal, Komal B, Bashir MA (2021b) Analysis of environmental taxes publications: a bibliometric and systematic literature review. Environ Sci Pollut Res 28:20700-20716. https:// doi.org/10.1007/s11356-020-12123-x

Bashir MF, MA B, Bashir MA, Bilal, Shahzad L (2021c) Scientific data-driven evaluation of academic publications on environmental Kuznets curve. Environ Sci Pollut Res 28:16982-16999. https:// doi.org/10.1007/s11356-021-13110-6 
Bashir MF, MA B, Qin Y, Bashir MA (2021g) Evaluation of One Belt One Road publications: a bibliometric and literature review analysis. Environ Sci Pollut Res 28:37016-37030. https://doi.org/10. 1007/s11356-021-14621-y

Bashir MA, Sheng B, Farooq MU, Bashir MF, Shahzad U (2021h) The role of macroeconomic and institutional factors in foreign direct investment and economic growth: empirical evidence in the context of emerging economies. Glob Local Econ Rev 24(2):56e72

Bashir MF, MA B, Hussain HI, Shahbaz M, Koca K, Shahzadi I (2022) Evaluating environmental commitments to COP21 and the role of economic complexity, renewable energy, financial development, urbanization, and energy innovation: empirical evidence from the RCEP countries. Renew Energy 184:541-550. https://doi.org/10. 1016/J.RENENE.2021.11.102

Bastianin A, Conti F, Manera M (2016) The impacts of oil price shocks on stock market volatility: evidence from the G7 countries. Energy Policy 98:160-169

Bjørnland HC (2009) Oil price shocks and stock market booms in an oil exporting country. Scott J Political Econ 56(2):232-254

Bouri E (2015) A broadened causality in variance approach to assess the risk dynamics between crude oil prices and the Jordanian stock market. Energy Policy 85:271-279

Boyer MM, Filion D (2007) Common and fundamental factors in stock returns of Canadian oil and gas companies. Energy Econ 29(3):428-453

Chang CL, McAleer M, Tansuchat R (2010) Analyzing and forecasting volatility spillovers, asymmetries and hedging in major oil markets. Energy Econ 32(6):1445-1455

Chen L, Zhao X, Tang O, Price L, Zhang S (2017) Supply chain collaboration for sustainability: a literature review and future research agenda. Int J Prod Econ. 194:73-87

Chen SS (2010) Do higher oil prices push the stock market into bear territory? Energy Econ 32(2):490-495

Chiou JS, Lee YH (2009) Jump dynamics and volatility: oil and the stock markets. Energy 34(6):788-796

Choi K, Hammoudeh S (2010) Volatility behavior of oil, industrial commodity and stock markets in a regime-switching environment. Energy Policy 38(8):4388-4399

Ciner C (2001) Energy shocks and financial markets: nonlinear linkages. Studies in Nonlinear Dynamics \& Econometrics 5(3)

Degiannakis, S., Filis, G., and Arora, V. (2018). Oil prices and stock markets: a review of the theory and empirical evidence. Energy J, 39(5).

El-Sharif I, Brown D, Burton B, Nixon B, Russell A (2005) Evidence on the nature and extent of the relationship between oil prices and equity values in the UK. Energy Econ 27(6):819-830

Faff RW, Brailsford TJ (1999) Oil price risk and the Australian stock market. J Energy Finance Dev 4(1):69-87

Fahimnia B, Sarkis J, Davarzani H (2015) Green supply chain management: a review and bibliometric analysis. Int J Prod Econ 162:101-114

Filis G, Degiannakis S, Floros C (2011) Dynamic correlation between stock market and oil prices: the case of oil-importing and oilexporting countries. Int Rev Financial Anal 20(3):152-164. https://doi.org/10.1016/j.irfa.2011.02.014

Fong WM, See KH (2002) A Markov switching model of the conditional volatility of crude oil futures prices. Energy Econ 24(1):71-95

Henriques I, Sadorsky P (2008) Oil prices and the stock prices of alternative energy companies. Energy Econ 30(3):998-1010

Hjørland B (2013) Facet analysis: The logical approach to knowledge organization. Inf Process Manag 49(2):545-557

Huang BN, Hwang MJ, Peng HP (2005) The asymmetry of the impact of oil price shocks on economic activities: an application of the multivariate threshold model. Energy Econ 27(3):455-476
Huang RD, Masulis RW, Stoll HR (1996) Energy shocks and finncial markets: Introduction. J Futures Mark 16(1):1. Retrieved from https://www.proquest.com/scholarly-journals/energy-shocks-finan cial-markets/docview/225490246/se-2?accountid=42594

Hussain M, Bashir MF, Shahzad U (2021) Do foreign direct investments help to bolster economic growth? New insights from Asian and Middle East economies. World J Entrep Manag Sustain Dev 17(1):62-84. https://doi.org/10.1108/WJEMSD-10-2019-0085

Jain A, Biswal PC (2016) Dynamic linkages among oil price, gold price, exchange rate, and stock market in India. Res Policy 49:179-185

Jones CM, Kaul G (1996) Oil and the stock markets. J Finance 51(2):463-491

Li H, An H, Wang Y, Huang J, Gao X (2016) Evolutionary features of academic articles co-keyword network and keywords co-occurrence network: based on two-mode affiliation network. Phys A Stat Mech Appl 450:657-669

Lin B, Su T (2020) Mapping the oil price-stock market nexus researches: a scientometric review. Int Rev Econ Finance 67:133-147

Liu B, Ma B, Bashir, M.F. (2018) Mechanism design of multi-attribute reverse auction on margin bid. Paper presented at the 2018 4th International Conference on Education Technology, Management and Humanities Science (ETMHS 2018)

Liu ML, Ji Q, Fan Y (2013) How does oil market uncertainty interact with other markets? An empirical analysis of implied volatility index. Energy 55:860-868

Ma B, Wang Y, Zhou Z, Lai Y, Zhou Z, Bashir MF (2021) Can controlling family involvement promote firms to fulfill environmental responsibilities?-Evidence from China. Manager Dec Econ. https://doi.org/10.1002/mde.3403

MA B, Zhang Y, Qin Y, Bashir MF (2021b) Optimal insurance contract design with "No-claim Bonus and Coverage Upper Bound" under moral hazard. Exp Syst Appl 178:115050. https://doi.org/ 10.1016/j.eswa.2021.115050

MA B, Tang Q, Qin Y, Bashir MF (2021c) Policyholder cluster divergence based differential premium in diabetes insurance. Manager Dec Econ 42(7):1793-1807. https://doi.org/10.1002/mde.3345

MA B, Ye J, Huang Y, Bashir MF (2021d) Research of two-period insurance contract model with a low compensation period under adverse selection. Manager Dec Econ 41(3):293-307. https://doi. org/10.1002/mde. 3100

Malik F, Hammoudeh S (2007) Shock and volatility transmission in the oil, US and Gulf equity markets. Int Rev Econ Finance 16(3):357-368

Mao G, Liu X, Du H, Zuo J, Wang L (2015a) Way forward for alternative energy research: a bibliometric analysis during 1994-2013. Renew Sustain Energy Rev 48:276-286

Mao G, Liu X, Du H, Zuo J, Wang L (2015b) Way forward for alternative energy research: a bibliometric analysis during 1994-2013. Renew Sustain Energy Rev 48:276-286

Miller JI, Ratti RA (2009) Crude oil and stock markets: stability, instability, and bubbles. Energy Econ 31(4):559-568

Nandha M, Faff R (2008) Does oil move equity prices? Global View Energy Econ 30(3):986-997

Narayan PK, Sharma SS (2011) New evidence on oil price and firm returns. J Bank Finance 35(12):3253-3262

Nazlioglu S, Gupta R, Bouri E (2020) Movements in international bond markets: the role of oil prices. Int Rev Econ Finance 68:47-58

Nomikos NK, Pouliasis PK (2011) Forecasting petroleum futures markets volatility: the role of regimes and market conditions. Energy Econ 33(2):321-337

Papapetrou E (2001) Oil price shocks, stock market, economic activity and employment in Greece. Energy Econ 23(5):511-532 
Park J, Ratti RA (2008) Oil price shocks and stock markets in the US and 13 European countries. Energy Econ 30(5):2587-2608

Radicchi F, Castellano C, Cecconi F, Loreto V, Parisi D (2004) Defining and identifying communities in networks. Proc Nat Acad Sci 101(9):2658-2663

Raza N, Shahzad SJH, Tiwari AK, Shahbaz M (2016) Asymmetric impact of gold, oil prices and their volatilities on stock prices of emerging markets. Res Policy 49:290-301

Rossetto DE, Bernardes RC, Borini FM, Gattaz CC (2018) Structure and evolution of innovation research in the last 60 years: review and future trends in the field of business through the citations and co-citations analysis. Scientometrics 115(3):1329-1363

Sadorsky P (1999) Oil price shocks and stock market activity. Energy Econ 21(5):449-469

Shahbaz M, Bashir MF, Bashir MA, Shahzad L (2021) A bibliometric analysis and systematic literature review of tourism-environmental degradation nexus. Environ Sci Pollut Res 1-17. https://doi.org/ 10.1007/s11356-021-14798-2

Sharif, A., Aloui, C., and Yarovaya, L. (2020). Covid-19 pandemic, oil prices, stock market and policy uncertainty nexus in the us economy: fresh evidence from the wavelet-based approach. Oil Prices, Stock Market and Policy Uncertainty Nexus in the US Economy: Fresh Evidence from the Wavelet-Based Approach (April 13, 2020).

Small H (1973) Co-citation in the scientific literature: a new measure of the relationship between two documents. J Am Soc Inf Sci 24(4):265-269

Sultan N, Mohamed N, Bashir MA, Bashir MF (2021) The anti-money laundering and counter financing of terrorism policy in Pakistan: is it truly combating or just a high-level desk work bureaucracy? J Public Aff e2731. https://doi.org/10.1002/pa.2731
Talbi B, Jebli MB, Bashir MF, Shahzad U (2020) Does economic progress and electricity price induce electricity demand: a new appraisal in context of Tunisia. J Public Aff :e2379 https://onlin elibrary.wiley.com/doi/full/10.1002/pa.2379

Tripathi M, Kumar S, Sonker S, Babbar P (2018) Occurrence of author keywords and keywords plus in social sciences and humanities research: a preliminary study. COLLNET J Scientomet Inf Manag 12(2):215-232

Wardikar, V. G., and Gudadhe, V. P. (2013). Application of Bradford's Law of scattering to the literature of library \& information science: a study of doctoral theses citations submitted to the Universities of Maharashtra, India. Library Philosophy and Practice, $0 \_1$.

Xia W, Apergis N, Bashir MF, Ghosh S, Doğan B, Shahzad U (2022) Investigating the role of globalization, and energy consumption for environmental externalities: empirical evidence from developed and developing economies. Renew Energy 183:219-228. https://doi.org/10.1016/J.RENENE.2021.10.084

Xu X, Chen X, Jia F, Brown S, Gong Y, Xu Y (2018) Supply chain finance: a systematic literature review and bibliometric analysis. Int J Prod Econ 204:160-173

Zhang K, Wang Q, Liang QM, Chen H (2016) A bibliometric analysis of research on carbon tax from 1989 to 2014. Renew Sustain Energy Rev 58:297-310

Zupic I, Čater T (2015) Bibliometric methods in management and organization. Org Res Methods 18(3):429-472

Publisher's note Springer Nature remains neutral with regard to jurisdictional claims in published maps and institutional affiliations. 